\title{
The Copper-Calcium Hydroxide Nanoparticles Galvanophoresis for Cleans-Ing Spaces of the Root of the Tooth
}

\author{
Vitaly Rumiantcev ${ }^{1 *}$, Galina Bordina ${ }^{2}$, Alisa Blinova ${ }^{3}$, Denis Moiseev ${ }^{3}$ and Iuliana Iusupova ${ }^{3}$ \\ ${ }^{1}$ Faculty of periodontology, The Tver Medical University, Tver, Russian Federation, Moscow, Russia \\ ${ }^{2}$ Faculty of the common chemistry, The Tver Medical University, Tver, Russian Federation, Moscow, Russia \\ ${ }^{3}$ Faculty of stomatology, I.M. Sechenov First Moscow State Medical University, Russian Federation, Russia
}

Submission: July 01, 2021; Published: July 16, 2021

*Corresponding author: Vitaly Rumiantcev, Managing Faculty of Periodontology, Tver medical University, Russian Federation, Moscow, Russia

\begin{abstract}
Have lead a clinic-laboratory estimation of a new way purification of roots spaces of a teeth at endodontic treatment chronic apical periodontitis with the help of nanoparticles copper-calcium hydroxide (CCH) galvanophoresis. In research with participation of 60 patients by a double-blind method have estimated quantitative dynamics and structure allocated of root channels of a single-root teeth of a liquid within 2 weeks with use of three different galvanic couple. Have compared efficiency of decontamination root channels at the standard report irrigation and CCH galvanophoresis. It is revealed that intensity of allocation of a liquid from root channels at CCH galvanophoresis is gradually increased to 4 - to 5 days, and then reduced to 10 - to 12 days. At an allocated liquid there are proteins and carbohydrates, characteristic pulps for the rests and a biofilm. CCH galvanophoresis suppresses aerobic and anaerobic micro-flora, then irrigation more effectively: on the average on $22,0 \%$ for 6 day and on $65,5 \%$ for 12 days. Modern endodontics the new paradigm representing a root of a tooth as porous biological structure that will allow to increase quality of treatment due to use nanotechnologys is necessary.
\end{abstract}

Keywords: Apical periodontitis; Nanotechnology; Treatment of the root channel; Endodontic irrigation

\section{Introduction}

Individual distinctions of anatomy of root channels of a teeth, variability of their number, the form and degree of passableness remain the reason of low efficiency endodontic treatments [1-3]. However, besides this problem there is also another - presence in dentine a root of the big number of dentine tubules. On $1 \mathrm{~mm}^{2}$ pathogenic or conditionally pathogenic microflora (biofilm) is necessary the area of a wall of the root channel up to 80000 apertures such tubules with diameter near $800 \mathrm{~nm}$, in which persist. This biofilm, remote for irrigants, results not only in formation of the chronic center odontogenic infections, but also to demineralization of a root dentine $[4,5]$. For today there is up to the end unsolved a question about effective purification systems of root channels of a teeth and dentine tubules a root from the albuminous rests of a pulp, components of a biofilm and products of its ability to live. Be-sides action antiseptic irrigants is limited on time and a degree of their penetration in dentine tubules $[6,7]$.

Modern ways of purification of endodontic spaces, such as use irrigant by sodium hypochlorite and other antiseptics, photodynamic inactivation microflorae, influence by ultrasound or cold plasma, time obturation antiseptic materials, do not allow to clear on $100 \%$ porous of dentine structure a root of the albuminous rests and microflora $[8,9]$. For treatment apical periodontitis of a teeth with difficultly passable root channels professor A. Knappwost (Germany, 1998) was offered a method "depotphoresis" a complex ionic preparation - copper-calcium hydroxide (CCH) [10,11]. Its updating is galvanophoresis at which instead of the electric device use galvanic pairs (galvanic pins) [12]. Particles CCH having the size $50-100 \mathrm{~nm}$, under action of a galvanic current easily will penetrate into spaces of a root of a tooth, switching and dentine tubules. Due to the chemical properties, they promote disintegration and destruction of biofilm extracellular matrix, chitinous environments microbic dispute, lysed the rests of cel-lular and fiber elements of a pulp. Being late in dentine tubules on long term, they actively destroy bacterial toxins, occlusive themselves narrow dentine tubules.

Galvanic pins in depth of the root channel of a tooth with $\mathrm{CCH}$ paste become a source of a galvanic current with potential near $0,5 \mathrm{~V}$ in and size near $0,1 \mathrm{~mA}$. Such current allows slowly, but in regular intervals and to big enough depth to deliver $\mathrm{CCH}$ 
nanoparticles in dentine tubules and also to cover them walls macro channel, additional channels and sleeves apical deltas. Procedure is painless, and during its reali-zation the tooth continues is high-grade to function. Being engaged on an extent more than 15 years studying of a method CCH galvanophoresis, we count, that its opportunities undervalued modern by endodontics. In particular, clinical supervision has shown, that in the beginning of realization of galvanophoresis procedures occurs active purification systems of the root channels, accompa-nying deproteinization and decontamination a root spaces of a tooth. The purpose of research: a clinic-laboratory estimation and a substantiation of a method purification a root spaces dentine of a tooth at endodontic treatment of apical periodontitis with the help by copper-calcium hy-droxide galvanophoresis.

\section{Material and Methods}

According to the purpose of research, have formulated the following tasks: (1) - at chronic apical periodonti-tis to study dynamics of allocation of a liquid from root channels of a teeth at realization in them $\mathrm{CCH}$ galvanophore-sis, and also its qualitative structure; (2) - to compare this dynamics at realization $\mathrm{CCH}$ galvanophoresis to applica-tion of three different galvanic pairs, distinguished in the size of potential of a galvanic current; (3) - to compare in-fluence of procedures $\mathrm{CCH}$ galvanophoresis and the standard report irrigation on microflora of root channels to the help of a microbiological method and electronic microscopy.

Research have lead a double blind method with participation of specially picked up patients - volunteers for which clinically and radiologically was diagnosed chronic fibrous apical periodontitis of a single-root teeth with kept crowns (52 cutters, 8 canines). On intraoral roentgenograms observed only expansion periodontal cracks or resorp-tion of a cortical plate. For reception of the most representative data in research with destructive forms of a periodon-titis or patients did not participate in a stage of its aggravation. Among patients appeared 24 men and 36 women in the age of from 22 till 56 years.
In total - 60 person which have any way united in 4 groups (on 15 people in every-one). After identical in all cases of tool processing of root channels with the help of rotating nickel-titanic tools ap-plied various ways cleansing systems of root channels. Ways were coded in a computer and are unknown to the head of research down to an analysis stage of the received data. In I group of patients applied the standard report irrigaton root channels with use of solutions sodium hypochlorite - 5,25\%, EDTA - $17 \%$, chlorhexidine bigluconate $-0,2 \%$, a citric acid - $50 \%$, distilled water and ultrasonic activation. After that root channels sealed up, that is used one-session a method of treatment. In other groups applied a new way cleansing root channel with the help CCH galvano-phoresis [12]. It consists of that root channels unitary washed out $17 \%$ solution EDTA and distilled water.

Then in them on 2/3 filled CCH paste and entered a galvanic element representing a galvanic pair (Figure 1). Intra radix part of an element as a needle (a bimetallic pin) consist of an alloy copper, and extra radix (head) - from other metal. In II group of patients for extra radix parts used chemically pure zinc, in III group - an alloy of aluminium and in IV - an alloy of magnesium. Real potential of elements determined with the help by voltmeter directly in a tooth after their introduc-tion in root channels. In wellhead a part of the channel placed identical on the sizes of foam balls for the subsequent gathering allocated in result electric osmosis from the root channel of a liquid. A cavity closed by time light-curing material so that to provide contact of the head of a galvanic element to an oral liquid. In quality CCH applied a preparation "Cupral" firms «Humanchemie GmbH» (Germany). Patients II - IV groups daily visited the doctor during 2 weeks except for revival. Each day at them deleted a time seal and foam balls. Last placed about a sterile plastic glass and carefully washed out its distilled water. A glass with a washing liquid dried up on air at 200 C. Remaining dry rest weighed on analytical weights, and also subjected to the spectrometer analysis. Into a cavity of a tooth entered a new foam ball and closed a time seal before the following visiting.

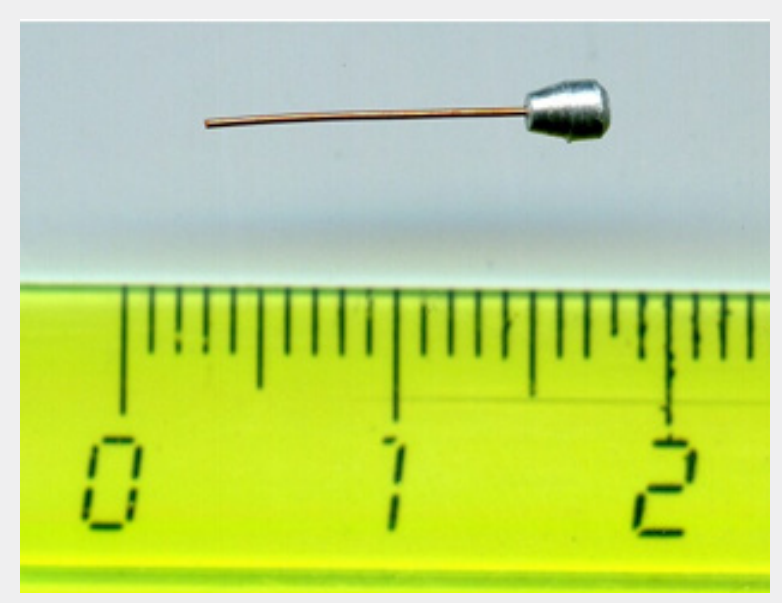

Figure 1: Results of the infra-red spectrometer analysis a liquid liberated from root channels of a teeth. 
All research in these three groups last 12 day (excepting revivals) and began on Mondays. On Wednesday of 1 week, Monday and environment (Wednesday) of 2 weeks in root channels changed $\mathrm{CCH}$ paste for a new portion and entered a new galvanic element. On Saturdays of 1 both 2 weeks a galvanic element and $\mathrm{CCH}$ paste from channels took and took tests of contents of the channel for microbiological research. On Sunday between two weeks a galvanic element took from the root channel and in it left only $\mathrm{CCH}$ paste. At 3 patients under indications a tooth for realization of further their research having chopped off on were removed an electronic microscope. At the patient who was not including in one of groups, - without realization of any procedures root channels cleansing. At two others - right after realizations of those procedures: in II group - after the report irrigation (1 tooth) and in III group - after realization CCH galvanophoresis for 6 day (1 tooth). All pa-tients were warned about necessity of removal of these teeth and gave the consent to participation in research.

Spectra of absorption by the dry rest of the liquid allocated from root channels, measured a method of the broken full internal reflection. The analyzed area of wave numbers made from 400 up to $4000 \mathrm{sM}-1$. A spectrum of absorption of air containing carbonic gas and pairs of water, automatically subtracted from a spectrum of a sample. Infra-red spectra of absorption registered on an infra-red spectrometer «Nicolet iS10» («Thermo SCIENTIFIC») with automatic record of a spectrum in the field of 400-4000 sM1 at speed of $64 \mathrm{sM}-1 / \mathrm{min}$. Processing of spectra spent in the computer program "OMNIC-2". For microbiological research a fence of a material spent the sterile paper pins impregnated with a physiolog-ical solution. A pin placed for 10 seconds in the root channel, and then - in the transport environment for delivery in laboratory. Colonies of microorganisms raised in Petry cups during 2 day in thermostat at temperature 36,70 C: aero-bic cultures - on Endo environments, Saburo, Columbia, M118 and the Streptococcal environment. Anaerobic - in bifidus environments and Schaedler. Colonies identified up to a sort and counted up. For research of the removed teeth with the help of an electronic microscope their roots split along root channels. Chipped carefully ground. Research spent in a tunnel electronic microscope «Tecnai G2 20F U-TWIN STEM» at accelerating voltage $20 \mathrm{kV}$. The received data having normal distribution, processed by variation statistical method with application of criterion " $t$ ". Research is approved by ethical committee of the Tver medical university. All surveyed gave the written informed consent to participation in research.

\section{Results and Discussion}

The potential of the used galvanic elements differed (Table 1). In the least potential the galvanic pair «copper - zinc», and the greatest - «copper - magnesium» had. Distinction between theoretical and real values of potential speaks electroresistance of fabrics of a tooth (2 - $10 \mathrm{ohms}$ ) and presence $\mathrm{CCH}$ at root channels. In clinic under influence $\mathrm{CCH}$ galvanophoresis, since the first day, we observed active allocation in a cavity of a tooth gel with a yellow shade (Figure 2). After drying a liquid received dense vitreous weight which subjected to the analysis. In the first day's process of cleansing most actively went in those teeth where used galvanic couples «copper - magnesium» with a maximum of this activity for 4 day (Figure 3). Hardly less active it was in a tooth where for $\mathrm{CCH}$ galvanophoresis applied galvanic pairs «copper aluminium» with a maximum on 5 days. And practically weight of the dry rest of a liquid down to 5 day in direct ratio accrued at application galvanic pairs «copper - zinc». After the expiration 4 5 day weight of the dry rest was slowly reduced at application of all galvanic pairs: about 12 day in a teeth with elements «copper - zinc», about 11 day - «copper - aluminium» and about 10 day at application galvanic pairs «copper - magnesium».

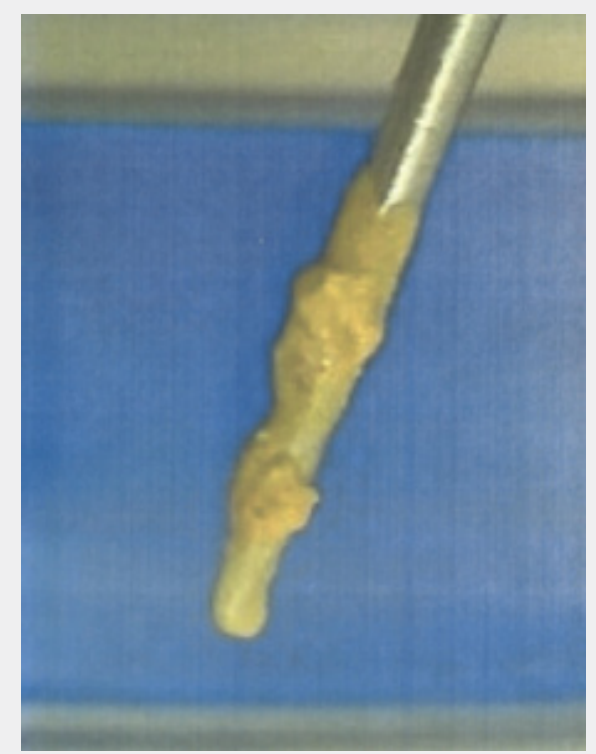

Figure 2: Liquid allocated from root channels at realization $\mathrm{CCH}$ galvanophoresis 


\section{Advances in Dentistry \& Oral Health}

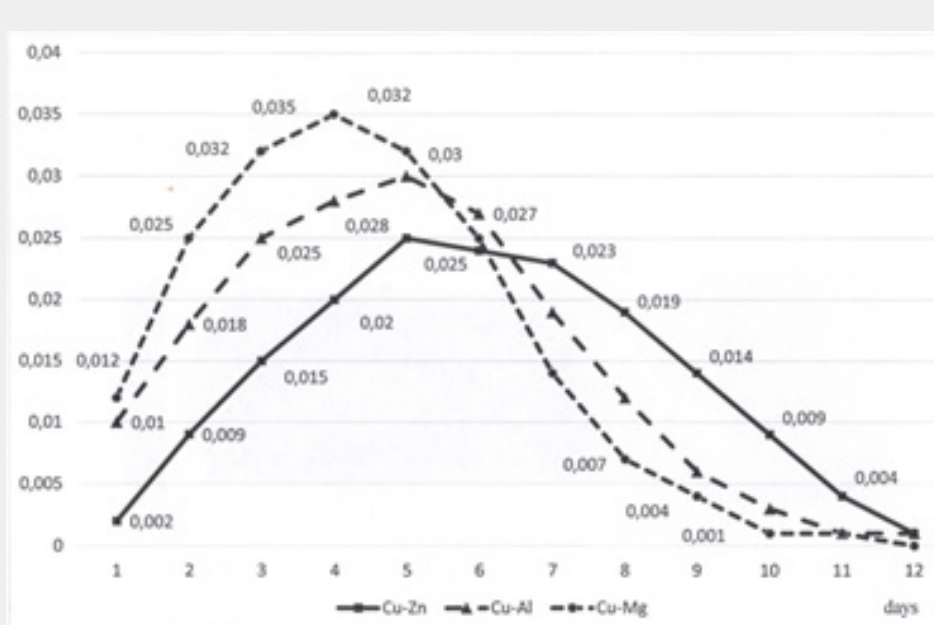

Figure 3: Changes of the received dry rest $(\mathrm{g})$ from allocated from root channels of a teeth of a liquid at realization $\mathrm{CCH}$ galvanophoresis with use of different galvanic pairs.

Table 1: Electric potential of galvanic elements with different galvanic pairs (V).

\begin{tabular}{|c|c|c|}
\hline Galvanic pairs & Theoretically & Really in a tooth (M $\mathbf{m}, \mathbf{n}=\mathbf{1 5})$ \\
\hline $\mathrm{Cu}-\mathrm{Zn}$ & 1,1 & $0,37 \pm 0,02$ \\
\hline $\mathrm{Cu}-\mathrm{Al}$ & 2,0 & $0,64 \pm 0,03$ \\
\hline $\mathrm{Cu}-\mathrm{Mg}$ & 2,7 & $0,87 \pm 0,03$ \\
\hline
\end{tabular}

The analysis of an infra-red spectrum of the dry rest of a liquid, liberated from root channels of a teeth, has shown presence in an analyzed sample of an organic component (Figure 4). Maxima testified to it in zones of the spec-trum, the appropriate 2917 and 2852 sM- 1 (symmetric and asymmetric fluctuations methylene groups). It is con-firmed also with a strip at $1397 \mathrm{sM}$ 1 , appropriate to deformation fluctuations of CH-groups. Besides appeared, that the researched material contains in the structure also a carbohydrate component. It is known that presence of a plenty hydroxyl groups in structure of carbohydrates results information of system of hydrogen connections specific to everyone connection. On an infra-red spectrum wide and intensive enough strip testified to it in the field of wave numbers $3500-3200 \mathrm{sM}-1$. In a spectrum of absorption weaker strips of absorption are visible in 1747 and 1651 sM- 1, characteristic for valent fluctuations carbonyl groups $\mathrm{S}=\mathrm{O}$ which alongside with $\mathrm{OH}$ groups are present at carbohydrates more often. In a spectrum of absorption of 862,9 sM- 1 were determined the strips appropriate to sulphidic groups, present in polysaccharides. Besides there were strips of absorption in the field of 1000-1100 sM- 1 caused by fluctuations of a skele-ton of a molecule (pyranose rings).

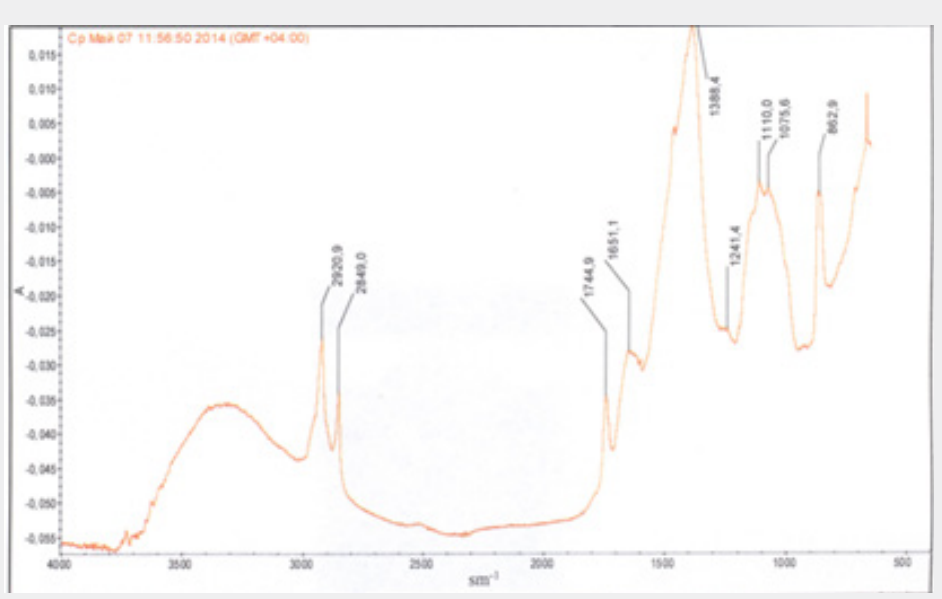

Figure 4: Infra-red spectra of absorption of the dry rest from allocated from root channels of a teeth of a liquid at realization $\mathrm{CCH}$ galvanophoresis. 


\section{Advances in Dentistry \& Oral Health}

Thus, the liquid, liberated from root channels of a teeth, besides albuminous components contain also the rests extracellular polysaccharides, being an obligatory component of a biofilm. We believe, that at $\mathrm{CCH}$ galvanophoresis from the root channel of a tooth the albuminous rests of microflora, and also fabrics of a pulp and contents den-tine tubules are actively allocated. It is marked, that the proportion of a carbohydrate component in the dry rest was gradually reduced with increase of duration galvanophoresis, that, apparently, corresponded decontamination systems of the root channel of a tooth. The kept albuminous component specified longer process of deproteinization. This conclusion also is confirmed with results of electron-microscopic research.
Without procedures cleansing on walls of root channels found out the numerous colonies of microorganisms closing apertures of dentine tubules (Figure 5a, 5B). The ambassador irrigation on walls of the root channel of microbe colonies became less and on electron diffraction apertures of dentine tubules (Figure 5c) were precisely visible. After 6 day of galvanophoresis apertures of dentine tubules visualized under an electronic microscope for the account contouring their walls $\mathrm{CCH}$ particles (Figure 5d). Besides sites inter tubules dentine, in part CCH impregnated were revealed. Apparently, it is sites which electroresistance is reduced due to microbe demineralization.
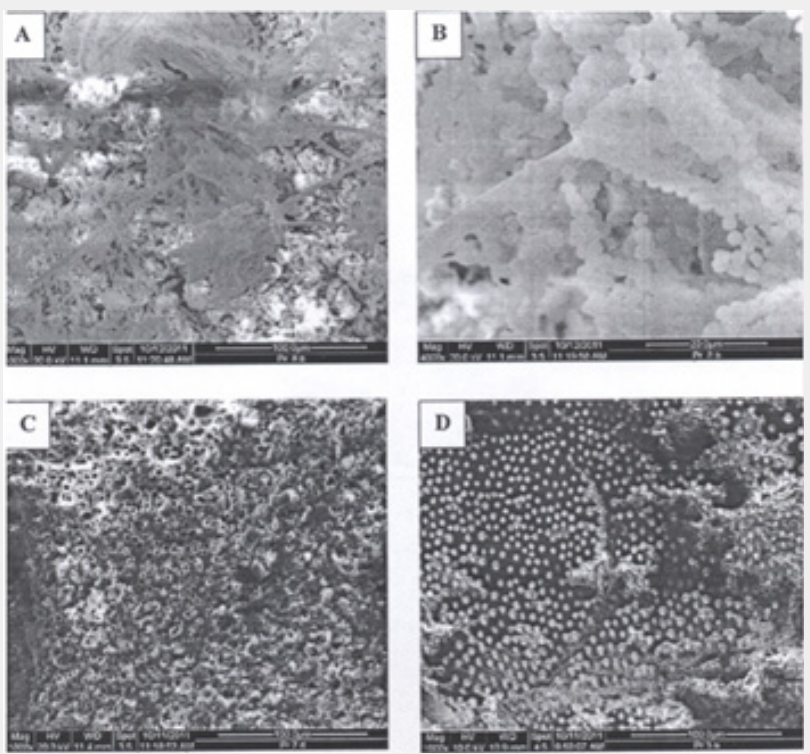

Figure 5: Surface of a wall of the root channel of a tooth: A and B - before procedures cleansing (colonies of microorganisms of a biofilm are visible); $\mathrm{C}$ - after the standard report irrigation (apertures dentine tubules are visible); $\mathrm{D}$ - after realization galvanophoresis within 6 day (dentine tubules and inter tubules dentine in part impregnated by nanoparticles $\mathrm{CHH}$ ). TEM, In. A, C and D $\times 1000$, B $-\times 4000$.

Table 2: Frequency of revealing of colonies of microorganisms in root channels of a teeth $(M \pm m, \Delta, p, n=15)$.

\begin{tabular}{|c|c|c|c|c|c|c|}
\hline $\begin{array}{c}\text { Colonies of micro- } \\
\text { organisms }\end{array}$ & $\begin{array}{c}\text { Before treat- } \\
\text { ment }\end{array}$ & $\begin{array}{c}\text { The ambassador } \\
\text { irrigation }\end{array}$ & $\boldsymbol{\Delta}$ & \multicolumn{3}{|c|}{ The ambassador CCH galvanophoresis with galvanic pairs "cop- } \\
per - zinc"
\end{tabular}

*- Probability of distinctions $p<0,05$. 
The microbiological analysis of contents of root channels of a teeth (Table 2) has shown, that in them up to cleansing prevails anaerobic microflora. The average of anaerobes colonies exceeded those among aerobes on $18,5 \%(\mathrm{p}<0,05, \mathrm{t}=2,7)$. From aerobic forms it is most of all revealed Enterococci, on the average on $25,0 \%$ it is less - than Streptococci and on 39,3\% - Peptokokki. The ambassador irrigation root channels of a teeth the reduction of number of anaerobes colonies has made on the average 52,5 $\%$, and aerobic microorganisms - 58,3\% $(\mathrm{p}<0,05)$. At the same time at realization $\mathrm{CCH}$ galvanophoresis during 6 and 12 day these numbers, accordingly, have made $68,5 \%$ and $66,7 \%(\mathrm{p}<0,05)$. And reduction of number of colonies of aerobic forms has made 93,2 $\%$ and $90,2 \%$, accordingly ( $\mathrm{p}<0,05$ ). That is, appeared, that procedure of $\mathrm{CCH}$ galvanophoresis is more effective irrigation on the average on 22,0\% at duration of 6 day and on $65,5 \%$ at duration of 12 days thus for 12 days with the help CCH galvanophoresis was inactivated on the average about $92 \%$ of microflora of root channels system.

\section{Conclusions}

The carried-out research confirms the known data that under influence $\mathrm{CCH}$ galvanophoresis occurs lysis fossils of a pulp and a microbe biofilm in spaces of root of a tooth. Under influence of powerful process electro osmosis of proteolysatis it is allocated from macro channel in a cavity of a tooth that is it is carried out deproteinization and decontamination not only systems of root channels, but also dentine tubules. The algorithm of $\mathrm{CCH}$ galvanophoresis includes double replacement in root channel $\mathrm{CCH}$ and a galvanic element during 10 - 12 days. The investigated way of cleansing root channels spaces of a teeth when it terms of treatment allow, can be effective alternative to known reports irrigation at endodontic treatment of apical periodontitis. Besides the spent research shows, that modern endodontic for qualitative treatment of a teeth the new paradigm representing a root of a tooth as porous biological structure is necessary. Such approach assumes development of essentially new technologies of cleansing all spaces of a root with the help by nanotechnology and mechanisms of delivery medical products nanoparticles in the remote sites of spaces root dentine.

\section{References}

1. Shemesh A, Levin A, Katzenell V, Joe Ben Itzhak, Oleg Levinson, et al. (2015) Prevalence of 3- and 4-rooted first and second mandibular molars in the Israeli population. J Endod 41(3): 338-342.

2. Johnstone M, Parashos P (2015) Endodontics and the ageing patient. Aust Dent J 60 Suppl 1: 20-27.

3. Shemesh A, Levin A, Katzenell V, Itzhak JB, Avraham Z et al. (2016) Root anatomy and root canal morphology of mandibular canines in Israeli population. Refuat Hapeh Vehashinayim 33(1): 19-23.

4. Chen JE, Nurbakhsh B, Layton G, Bussmann M, Kishen A (2014) Irrigation dynamics associated with positive pressure, apical negative pressure and passive ultrasonic irrigations: a computational fluid dynamics analysis. Aust Endod J 40(2): 54-60.

5. Harlamb SC (2016) Management of incompletely developed teeth requiring root canal treatment. Aust Dent J 61(Suppl1): 95-106.

6. Plotino G, Cortese T, Grande NM. et al. (2016) New technologies to improve root canal disinfection. Braz Dent J 27(1): 3-8.

7. Berutti E, Marini R, Angeretti A (1997) Penetration ability of different irrigants into dentinal tubules. J Endodont 23(12): 725-727.

8. Lei-Meng J, Lak B, Eijsvogels LM, Wesselink PR, Van der Sluis LWM (2012) Comparison of the cleaning efficacy of different final irrigation techniques. J Endodont 38(6): 838-841.

9. Van der Waal SV, Connert T, Laheij AMGA, De Soet JJ, Wesselink PR (2014) Free available chlorine concentration in sodium hypochlorite solutions obtained from dental practices and intended for endodontic irrigation: Are the expec-tations true? Quintessence Int 45 (4): 467474 .

10. Knappwost A (1998) Erstmals physiologische Ausheilung und Sterilisation des Kanalsystems. DZW Special 11: 33-34.

11. Knappwost A (1998) Physikalisch Chemische High Tech fireine Neue Endodontie am Beispiei der Kupfer-Calciumhydroxid-Depotphorese. DZW Special 11: 33.

12. Rumjantsev VA, Rodionova EG, Denis AG, Olhovskaja AV, Tsaturova YuV (2013) Electronic microscopy in endodontic electrophoresis efficiency assessment. Stomatology (Moscow) 92(2): 4-8.
Your next submission with Juniper Publishers will reach you the below assets

- Quality Editorial service

- Swift Peer Review

- Reprints availability

- E-prints Service

- Manuscript Podcast for convenient understanding

- Global attainment for your research

- Manuscript accessibility in different formats

( Pdf, E-pub, Full Text, Audio)

- Unceasing customer service

Track the below URL for one-step submission https://juniperpublishers.com/online-submission.php 